\title{
Dihydroartemisinin/miR-29b combination therapy increases the pro-apoptotic effect of dihydroartemisinin on cholangiocarcinoma cell lines by regulating Mcl-1 expression
}

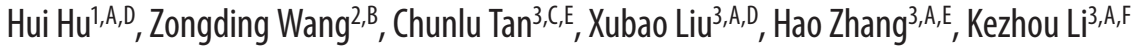 \\ ${ }^{1}$ Department of Traumatology, Central Hospital of Chongqing University, Chongqing Emergency Medical Center, China \\ ${ }^{2}$ Department of General Surgery, Peoples's Hospital of Fengjie, Chongqing, China \\ ${ }^{3}$ Departments of Pancreatic Surgery, West China Hospital, Sichuan University, Chengdu, China \\ A - research concept and design; B - collection and/or assembly of data; C - data analysis and interpretation; \\ $D$ - writing the article; $E$ - critical revision of the article; $F$ - final approval of the article
}

Address for correspondence

Kezhou Li

E-mail: likezhou11@126.com

Funding sources

None declared

Conflict of interest

None declared

Received on July 29, 2018

Reviewed on November 25, 2018

Accepted on May 1,2020

Published online on August 13, 2020

Cite as

Li K, Hu H, Wang Z, Tan C, Liu X, Zhang H. Dihydroartemisinin/ miR-29b combination therapy increases the pro-apoptotic effect of dihydroartemisinin on cholangiocarcinoma cell lines by regulating Mcl-1 expression. Adv Clin Exp Med. 2020:29(8):911-919. doi:10.17219/acem/121919

DOI

10.17219/acem/121919

Copyright

Copyright by Author(s)

This is an article distributed under the terms of the

Creative Commons Attribution 3.0 Unported (CC BY 3.0)

(https://creativecommons.org/licenses/by/3.0/)

\begin{abstract}
Background. Cholangiocarcinoma is a malignant tumor that originates from the neoplastic transformation of bile duct epithelial cells.

Objectives. To investigate the role of DHA and miR-29b on the proliferation and apoptosis of cholangiocarcinoma cells, and to explore whether DHA exerted its role through the miR-29b/Mcl-1 signaling pathway.

Material and methods. Human cholangiocarcinoma cell lines HUCCT-1 and FRH0201 were treated with dihydroartemisinin (DHA) and DHA+miR-29b. The inhibitory effects of DHA and miR-29b on proliferation were detected using MTT assay. The effects of DHA and miR-29b on apoptosis were detected using flow cytometry (FCM). The mRNA and protein expressions of Mcl-1L and Mcl-1S were evaluated with reverse transcriptase polymerase chain reaction $(R T-P(R)$ and western blotting, respectively.

Results. The DHA increased miR-29b expression in HUCCT-1 and FRH201 cells. The MTT assay showed that DHA+miR-29b combination therapy promoted the inhibition effects on the proliferation of HUCCT-1 and FRH201 cells. The FCM results revealed that DHA and miR-29b combination therapy increased the apoptosis of HUCCT-1 and FRH201 cells. The RT-PCR and western blotting analysis found that DHA+ miR-29b combination therapy significantly decreased Mcl-1L expression and increased Mcl-1S expression in both HUCCT-1 and FRH201 cells. The Mcl-1S:Mcl-1L ratio was notably higher in the DHA+miR-29b combination therapy group than in the control group and DHA therapy group, in both HUCCT-1 and FRH201 cells.
\end{abstract}

Conclusions. The DHA and miR-296 have a pro-apoptotic effect on cholangiocarcinoma cells through the DHA/miR-29b/Mcl-1 pathway, possibly by upregulating the expression of the pro-apoptotic protein Mcl-1S and thus increasing the proportion of $\mathrm{MCl}-15$ protein among the total amount of $\mathrm{MCl}-1$ protein.

Key words: cholangiocarcinoma, miR-29b, dihydroartemisinin, Mcl-1 


\section{Introduction}

Cholangiocarcinoma is a malignant tumor that originates from the neoplastic transformation of bile duct epithelial cells, with a particularly high prevalence in Eastern Asia. ${ }^{1}$ The malignancy is usually diagnosed at an advanced stage and is already inoperable; compared with other gastrointestinal tumors, it has a poorer response to chemotherapy. ${ }^{2}$ While no major advance has been made in investigating pathogenesis and establishing therapy of cholangiocarcinoma, the anti-tumor activity of dihydroartemisinin (DHA) has been widely recognized. ${ }^{3,4}$ Compared with artemisinin, dihydroartemisinin is more water-soluble, more absorbable and more effective against malaria. ${ }^{5-7}$ A recent study has demonstrated that DHA can promote apoptosis of tumor cells by changing cell autophagy. ${ }^{8,9}$

The protein product encoded by Mcl-1 is a member of the Bcl-2 anti-apoptosis gene family. After transcription, this gene can produce a variety of transcripts through different splicing approaches. Specifically, the longest transcript-encoded gene product, myeloid cell leukemia Mcl-1L, can improve cell survival by inhibiting apoptosis, while the shorter gene product, $\mathrm{Mcl}-1 \mathrm{~S}$, has a pro-apoptotic effect and induces cell death. ${ }^{10,11}$ The miRNAs are a class of single-strand, noncoding small RNA molecules (19-25 nucleotides) which play a critical role in various processes, including cell growth, tissue differentiation, and the development and progression of malignant tumors. ${ }^{12,13}$ By complete or incomplete complementary pairing with the mRNA 3' untranslated region (UTR) of target genes, they can inhibit or block the translation of target genes without affecting mRNA stability. Abnormal miR-29b expression is often closely associated with abnormal apoptotic signaling pathways of tumor cells. The overexpression of $m i R-29 b$ in cells results in a decreased Mcl-1 protein expression. Also, $m i R-29 b$ expression is elevated in normal immortalized bile duct cells and decreased in malignant cholangiocarcinoma cell lines. ${ }^{14,15}$ The regulation of endogenous miRNA (e.g., $m i R-29$ ) may provide a new treatment for cholangiocarcinoma. ${ }^{14,15}$ In our previous study, we found that DHA affected the expression of the apoptosis-associated protein Md-1 through multiple mechanisms, and that DHA therapy increased the Mcl-1S:Mcl-1L protein ratio, thus inducing apoptosis in cholangiocarcinoma cells (QBC939). ${ }^{16}$ HUCCT-1 and FRH0201 cell lines are also classic cholangiocarcinoma cell lines. In order to exclude cell specificity, these 2 cell lines were used in this study.

In the current study, we observed the effects of DHA therapy and $\mathrm{DHA}+m i R-29 b$ combination therapy on human cholangiocarcinoma cell lines HUCCT-1 and FRH0201, observed their effects on Mcl-1 expression, explored whether DHA exerted its role through the $m i R-29 b / \mathrm{Mcl}-1$ signaling pathway, and investigated the potential role of $\mathrm{DHA}+m i R-29 b$ combination therapy in cholangiocarcinoma.

\section{Material and methods}

\section{Cell lines and main reagents}

HUCCT-1 and FRH0201 cell lines were obtained as a courtesy of the Cell Center of Hsiang-ya Medical College, Hunan, China. The DHA was purchased from Sciphar Biotechnology Co. Ltd. (Xian, China). Tetrazolium salt MTT (3-[4,5-dimethylthiazol-2-yl]-2,5-diphenyl tetrazolium bromide), dimethyl sulfoxide (DMSO), Triton-100 and TRIzol were purchased from Sigma Chemical Co. (St. Louis, USA). The $m i R-29 b$ and its transfection kit were purchased from Guangzhou RiboBio Co. Ltd. (Guangzhou, China). Fetal bovine serum was purchased from Zhejiang Tianhang Biological Technology Co. Ltd. (Huzhou, China). RPMI-1640 culture medium and trypsin were purchased from Gibco (Grand Island, USA). A BCA protein assay kit was purchased from Beyotime (Haimen, China). Mcl-1 gene primers and probes were purchased from Sangon Biotech (Shanghai, China), and Mcl-1 antibody was sourced from Bioss (Beijing, China).

\section{Cell culture and treatment}

The HUCCT-1 and FRH0201 cell lines were cultured at $37^{\circ} \mathrm{C}$ in an atmosphere of $5 \% \mathrm{CO}_{2}$ in RPMI-1640 medium containing $10 \%$ bovine calf serum and $100 \mathrm{U} / \mathrm{mL}$ of a penicillin-streptomycin solution, as specified by the American Type Culture Collection (Manassas, USA). The cells grew adherently and were passaged every 2-3 days. During cell passage, the old culture medium was removed and the cells were washed twice with phosphate-buffered saline (PBS). After the cells were digested with $0.25 \%$ trypsin, they were centrifuged at 1,000 rpm for $7 \mathrm{~min}$, re-suspended in fresh medium and seeded into tissue culture flasks. After this step, $5 \mathrm{nmol}$ of lyophilized miR-29b RNA powder was dissolved in $250 \mu \mathrm{L}$ of sterilized deionized distilled water to prepare $20 \mu \mathrm{M}$ of stock solution. After the fibroblasts were at the $2^{\text {nd }}$ and $3^{\text {rd }}$ passages, they were subcultured and inoculated in six-well plates. After the cells were at $60-70 \%$ confluence, $m i R-29 b$ RNA was added; the cells were then further cultured in a constant-temperature incubator $\left(5 \% \mathrm{CO}_{2}\right.$ at $\left.37^{\circ} \mathrm{C}\right)$.

\section{Detection of the inhibitory effect of DHA on proliferation using an MTT assay}

We performed the MTT assay in order to choose the best DHA concentration - one that would be effective and low-toxic. We found that $20 \mu \mathrm{mol} / \mathrm{L}$ of DHA met the requirement. The cells were divided into 3 groups: a control group, treated with $0.1 \%$ DMSO only $(0 \mu \mathrm{mol} / \mathrm{L} \mathrm{DHA})$; a DHA therapy group, treated with $20 \mu \mathrm{mol} / \mathrm{L}$ of DHA; and a DHA $+m i R-29 b$ combination therapy group, treated with $20 \mu \mathrm{mol} / \mathrm{L}$ of DHA and miR-29b. Six duplicate wells were set up for each group. HUCCT-1 and FRH0201 cells in the logarithmic growth phase were collected. After cell 
counting, the cells were inoculated into 96 -well plates and routinely cultured for $24 \mathrm{~h}$ (with $10^{5}$ cells in $200 \mu \mathrm{L}$ in each well). The DHA was added to a final concentration of $20 \mu \mathrm{mol} / \mathrm{L}$ for the DHA group. For the control group, an equal volume of $0.1 \%$ DMSO was added; for the $3^{\text {rd }}$ group, DHA was added to a final concentration of $20 \mu \mathrm{mol} / \mathrm{L}$, together with $m i R-29 b$ and a transfection agent. The mixture was cultured at $37^{\circ} \mathrm{C}$ in an environment with saturated humidity and $5 \% \mathrm{CO}_{2}$ for $12 \mathrm{~h}, 24 \mathrm{~h}$ and $48 \mathrm{~h}$. Each well was treated with $20 \mu \mathrm{L}$ of MTT and then cultured for a further $4 \mathrm{~h}$ before the culture was terminated. The culture supernatant was discarded and $150 \mu \mathrm{L}$ of DMSO was added to each well, followed by discoloration and oscillation for $10 \mathrm{~min}$, so that the crystalline material was dispersed homogeneously. Absorbance was measured spectrophotometrically at $490 \mathrm{~nm}$, and the growth inhibition rate was calculated.

\section{Detection of apoptosis using flow cytometry and caspase $3 / 7$ activity apoptosis assay}

The harvested cells were inoculated in $25-\mathrm{cm}^{2}$ culture flasks ( $15 \mathrm{~mL} /$ well). After routine culturing for $24 \mathrm{~h}$, they were grouped as described for the MTT assay, with $6 \mathrm{du}-$ plicate wells in each group. In the experimental group, the cells were treated with $20 \mu \mathrm{mol} / \mathrm{L}$ of DHA and then cultured at $37^{\circ} \mathrm{C}$ in an environment with saturated humidity and $5 \% \mathrm{CO}_{2}$ for $12 \mathrm{~h}, 24 \mathrm{~h}$ and $48 \mathrm{~h}$. The HUCCT-1 and FRH0201 cells were digested with $0.25 \%$ trypsin. After the mixture was suspended and centrifuged at 1,000 rpm for $5 \mathrm{~min}$ and the supernatant was discarded, the cells were washed twice with $0.01 \mathrm{~mol} / \mathrm{L}$ of PBS. After the cells were fixed in precooled $70 \%$ ethanol at $4^{\circ} \mathrm{C}$ for $1 \mathrm{~h}$, the mixture was centrifuged at $1,000 \mathrm{rpm}$ for $5 \mathrm{~min}$; then, the supernatant was discarded and the cells were washed twice with $0.01 \mathrm{~mol} / \mathrm{L}$ of PBS. Add $1 \mathrm{~mL}$ of $0.01 \mathrm{~mol} / \mathrm{L}$ PBS, followed by the addition of RNAase $\mathrm{A}$ and propidium iodide to a final concentration of $50 \mu \mathrm{g} / \mathrm{mL}$ for the HUCCT-1 cells and $100 \mu \mathrm{g} / \mathrm{mL}$ for the FRH0201 cells. Then, the mixture was stored in the dark at $4^{\circ} \mathrm{C}$ for $30 \mathrm{~min}$. Finally, the cells were examined using flow cytometry (FCM). We also used a Caspase 3/7 Activity Apoptosis Assay Kit (E607103-0200; Sangon Biotech) to detect apoptosis by evaluating the relative fluorescence units.

\section{Detection of Mcl-1 mRNA expression using reverse transcriptase polymerase chain reaction ( $R T-P C R)$}

$\beta$-actin was used as an internal control. The experimental grouping was the same as in the MTT assay. Total RNA isolation is briefly described below. In a two-milliliter tube with mechanically disrupted tissue sample, $1 \mathrm{~mL}$ of TRIzol was added, vortexed well, and incubated for $5 \mathrm{~min}$ at room temperature. Chloroform was added $(0.2 \mathrm{~mL}$ per $1 \mathrm{~mL}$ of TRIzol) for homogenization. The sample was vortexed very well and incubated for $3 \mathrm{~min}$ at room temperature. Then, the samples were centrifuged at maximum speed on table microcentrifuge for $5 \mathrm{~min}$ at $+4^{\circ} \mathrm{C}$. The aqueous phase was transferred to a fresh microcentrifuge $2 \mathrm{~mL}$ tube with an equal volume of chloroform, vortexed well and then spun at maximum speed on table microcentrifuge for $5 \mathrm{~min}$. The aqueous phase was transferred to a fresh microcentrifuge two-milliliter tube with an equal volume of 2-propanol, vortexed well and then spun at maximum speed on table microcentrifuge at room temperature for $10 \mathrm{~min}$ at $+4^{\circ} \mathrm{C}$. The pellets were washed once with $1.5 \mathrm{~mL}$ of $70 \%$ ethanol and spun at maximum speed on table microcentrifuge for $5 \mathrm{~min}$. Next, the pellets were dissolved in $400 \mu \mathrm{L}$ of $1 \times \mathrm{TE}$ at $55^{\circ} \mathrm{C}$ for about $10 \mathrm{~min}$, with vortex. An equal volume of $10 \mathrm{M} \mathrm{LiCl}$ was added and the solution was chilled at $-20^{\circ} \mathrm{C}$ for several hours (overnight). Afterwards, the solution was spun at maximum speed on table microcentrifuge for $10 \mathrm{~min}$ at $+4^{\circ} \mathrm{C}$. The supernatants were carefully removed and discarded. The pellets were then washed with $1.5 \mathrm{~mL}$ of $70 \%$ ethanol, vortexed well and micro-centrifuged, and the ethanol was discarded. Next, the pellets were dissolved in $200 \mu \mathrm{L}$ of fresh milliQ water. Finally, $2 \mu \mathrm{g}$ RNA was used for the RT-qPCR experiments.

With mRNA as the template, cDNA was synthesized using random hexamer primers. Based on the sequences of 2 transcripts of Mcl-1 in GenBank (MCL1-001, representing Mcl-1L, and MCL1-002, representing Mcl-1S), the primer and probe sequences of Mcl-1-related genes and the $\beta$-actin gene were designed as follows: upstream primer sequence of Mcl-1L - 5'-TTTGGCTACGGAGAAGGAGG-3'; downstream primer sequence of Mcl-1L - 5'-TTCCGAAGCATGCCTTGGAAG-3' (597-bp sequence fragment); upstream primer sequence of Mcl-1S - 5'-CCGCTTGAGGAGATGGAAG-3'; downstream primer sequence of Mcl-1S -5'-CACAAACCCATCCTTGGAAG-3' (382-bp sequence fragment); upstream primer sequence of miR-29b - 5'-GTTTCATATGGTGGTTTAGAT-3'; downstream primer sequence of miR-29b - 5'-GAACACTGATTTCAAATGGT-3' (61-bp sequence fragment); upstream primer sequence of $\beta$-actin - 5'-GAAGATCAAGATCATTGCTCCT-3'; downstream primer sequence of $\beta$-actin - 5'-TACTCCTGCTTGCTGATCCA-3'; probe - 5'-FAM-CTGTCCACCTTCCAGCAGA-TAMRA-3' (111-bp sequence fragment). The amplification conditions were as follows: initial denaturation at $94^{\circ} \mathrm{C}$ for $2 \mathrm{~min}$, followed by 45 cycles of denaturation at $94^{\circ} \mathrm{C}$ for $20 \mathrm{~s}$, annealing at $53^{\circ} \mathrm{C}$ for $30 \mathrm{~s}$ and extension at $60^{\circ} \mathrm{C}$ for $40 \mathrm{~s}$. After the reaction was completed, Sequence Detection software v. 1.2.3 (Applied Biosystems, Foster City, USA) was used to analyze the threshold cycle (Ct) values of each sample. The specificity of PCR was judged according to the agarose gel electrophoresis and melting curves. The $2^{-\Delta \Delta C t}$ method is a convenient way to analyze the relative changes in gene expression from reverse transcriptase quantitative polymerase chain reaction (RT-PCR) experiments. ${ }^{17,18}$ Relative quantitative analysis was performed based on the $2^{-\Delta \Delta C t}$ method. 


\section{Detection of $\mathrm{Mcl}-1$ protein expression with western blotting}

The collected cells were uniformly seeded in $75-\mathrm{cm}^{2} \mathrm{cul}-$ ture plates $(10 \mathrm{~mL} /$ well $)$ and inoculated for $24 \mathrm{~h}$. The grouping was the same as described in the MTT assay. After the cells were cultured at $37^{\circ} \mathrm{C}$ in an environment with saturated humidity and $5 \% \mathrm{CO}_{2}$ for $48 \mathrm{~h}$, the old culture medium was discarded, and the cells were washed twice with $0.01 \mathrm{~mol} / \mathrm{L}$ of PBS. In each well, $0.01 \mathrm{~mol} / \mathrm{L}$ of PBS was added, and the cells were collected and centrifuged at $1,000 \mathrm{rpm}$ for $5 \mathrm{~min}$. Protein extracts were obtained by homogenizing the samples in lysis buffer (R0278; SigmaAldrich, Welwyn Gardens City, UK), followed by centrifugation at $4^{\circ} \mathrm{C}$ at $13,000 \mathrm{rpm}$ for $15 \mathrm{~min}$. Protein concentration was determined with the BCA protein assay method (23227; Thermo Fisher Scientific, Loughborough, UK). Equal amounts of protein $(20 \mu \mathrm{g})$ were loaded per lane for electrophoresis. The separated proteins were transferred to polyvinylidene difluoride (PVDF) membranes, then blocked at room temperature for $3 \mathrm{~h}$ and inoculated at $4^{\circ} \mathrm{C}$ overnight. The membranes were washed, and the mixture was treated with rabbit anti-human Mcl-1 primary antibody. After inoculation at $37^{\circ} \mathrm{C}$ for $2 \mathrm{~h}$, blocking solution and goat anti-rabbit IgG secondary antibody were added. Following inoculation at $37^{\circ} \mathrm{C}$ for $2 \mathrm{~h}$, the mixture was held in a shaking water bath with 1X PBS 3 times ( 5 min each). After color development and photography, the expression of Mcl-1L, Mcl-1S, and $\beta$-actin was analyzed using Quantity One software v. 4.4.0 (Bio-Rad Laboratories, Inc., Hercules, USA).

\section{Statistical analysis}

The measurement data are presented as means \pm standard deviation (SD). Comparison of the means between 2 groups was performed using Student's t-test. A p-value $<0.05$ was considered to indicate a statistically significant difference.

A

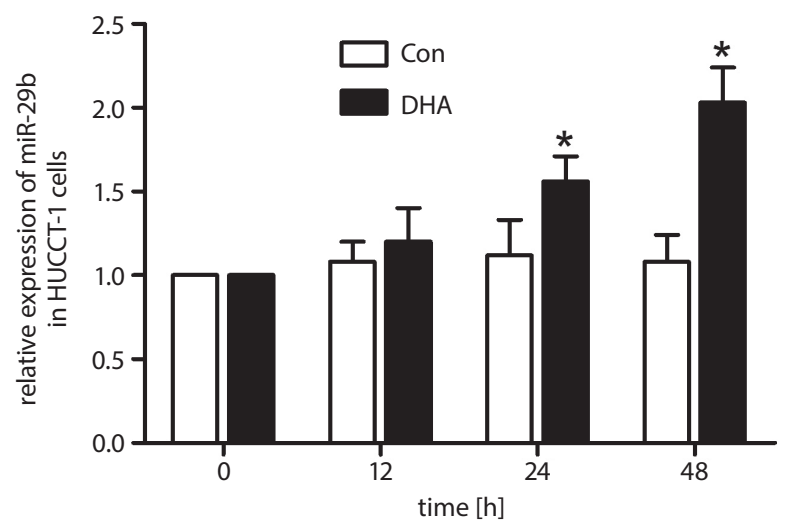

\section{Results}

\section{Effects of DHA on miR-29b expression level in HUCCT-1 and FRH201 cells}

We used DHA to treat the HUCCT-1 and FRH201 cells, and then evaluated $m i R-29 b$ expression. The DHA therapy significantly increased the expression of $m i R-29 b$ at $48 \mathrm{~h}$ in the HUCCT-1 cells compared with the level in the control group (Fig. 1A). The expression of $m i R-29 b$ in the FRH201 cells began to increase after $24 \mathrm{~h}$, and the level of $m i R-29 b$ was significantly higher than that of the control group after $48 \mathrm{~h}$ (Fig. 1B).

\section{DHA and miR-29b combination therapy promoted the inhibition effects on the proliferation of HUCCT-1 and FRH201 cells}

As shown using MTT assay, treatment with DHA $(20 \mu \mathrm{mol} / \mathrm{L})$ or DHA and $m i R-29 b$ for $12 \mathrm{~h}$ significantly inhibited the proliferation of HUCCT-1 cells, and such inhibitory effects increased over time. Statistical analysis revealed that the inhibition rate significantly differed between the DHA $+m i R-29 b$ and DHA groups at $12 \mathrm{~h}$, $24 \mathrm{~h}$ and $48 \mathrm{~h}(\mathrm{p}<0.01$, Fig. 2A).

Treatment with DHA for 12 h significantly inhibited the proliferation of FRH0201 cells, and DHA $+m i R-29 b$ combination therapy for $24 \mathrm{~h}$ significantly inhibited the proliferation of FRH0201 cells (Fig. 2B). Such inhibitory effects became more apparent over time, and the inhibition rate reached $87.3 \%$ at 48 h. Statistical analysis revealed that cell proliferation was significantly inhibited in the DHA $+m i R-29 b$ group at $24 \mathrm{~h}$, and in both the DHA and DHA $+m i R-29 b$ groups at $48 \mathrm{~h}(\mathrm{p}<0.01$, Fig. $2 \mathrm{~B})$. In addition, the FRH0201 cell growth inhibition rates were also significantly higher in the DHA+miR-29b group when compared with those in DHA group at $24 \mathrm{~h}$ and $48 \mathrm{~h}(\mathrm{p}<0.05$, Fig. 2B).
B

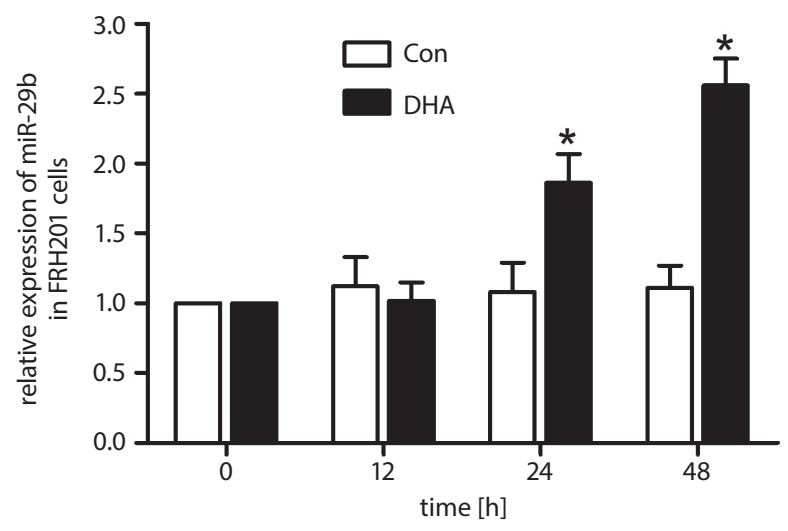

Fig. 1. Effects of DHA on miR-29b expression in HUCCT-1 and FRH201 cells. A. Effects on HUCCT-1 cells. B. Effects on FRH201 cells 
A

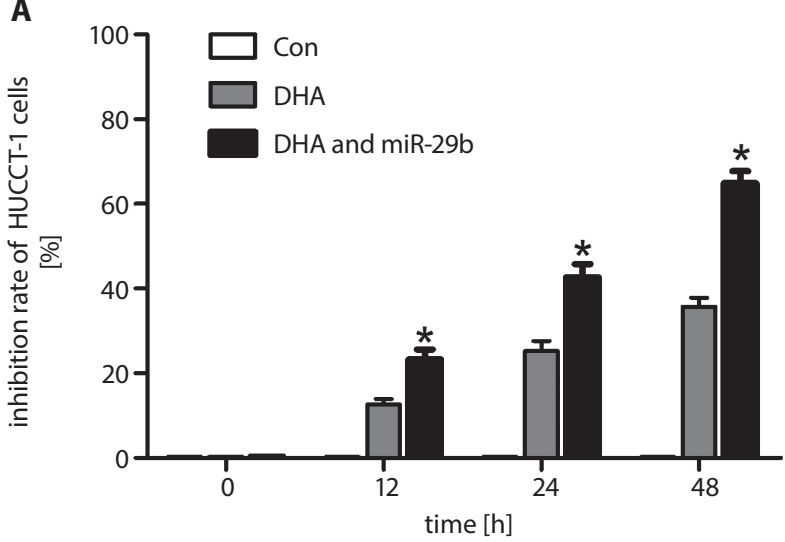

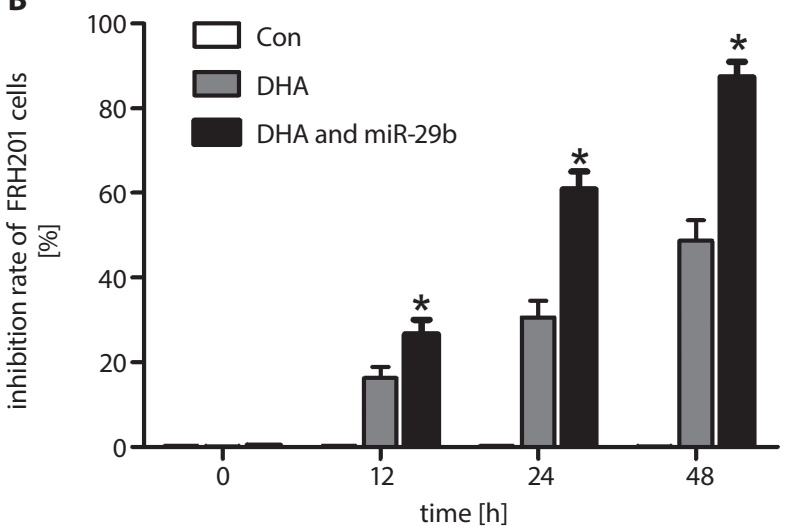

Fig. 2. Inhibitory effects of DHA and miR-29b on the growth of HUCCT-1 and FRH201 cells. A. Changes in growth inhibition rate of HUCCT-1 cells after treatment with $20 \mu \mathrm{mol} / \mathrm{L}$ of DHA or DHA and miR-29b. B. Changes in growth inhibition rate of FRH0201 cells after treatment with $20 \mu \mathrm{mol} / \mathrm{L}$ of DHA or DHA and miR-29b

* $p<0.05$ vs DHA group.

\section{Effects of DHA therapy and DHA+miR-29b combination therapy on apoptosis of HUCCT-1 and FRH201 cells}

The detection of apoptosis using FCM and caspase-3 relative fluorescence units (RFU) showed that, in comparison with the control group, treatment with $20 \mu \mathrm{mol} / \mathrm{L}$ of DHA alone or DHA $+m i R-29 b$ combination therapy significantly increased the apoptosis of HUCCT-1 cells at $24 \mathrm{~h}$ and $48 \mathrm{~h}$ (Fig. 3A,C; $\mathrm{p}<0.01$ ). The apoptosis rate at $48 \mathrm{~h}$ was significantly higher in the combination therapy group than in the DHA group (Fig. 3A). Compared with the control group, treatment with $20 \mu \mathrm{mol} / \mathrm{L}$ of DHA alone or with $\mathrm{DHA}+m i R-29 b$ significantly increased the apoptosis rate of FRH201 cells at $24 \mathrm{~h}$ and $48 \mathrm{~h}$ (Fig. 3B and 3D; p < 0.01). The apoptosis rate at $24 \mathrm{~h}$ and $48 \mathrm{~h}$ was significantly higher in the combination therapy group than in the DHA group (Fig. 3B,D; $\mathrm{P}<0.01$ ).

\section{Effects of DHA therapy and DHA+miR-29b combination therapy on Mcl-1 mRNA expression}

Reverse transcriptase fluorescence quantitative PCR (qPCR) revealed that $\mathrm{Mcl}-1 \mathrm{~L}$ and $\mathrm{Mcl}-1 \mathrm{~S}$ genes were expressed in the HUCCT-1 and FRH0201 cells. In the HUCCT-1 cell line, Mcl-1L gene expression significantly decreased $24 \mathrm{~h}$ after treatment with $20 \mu \mathrm{mol} / \mathrm{L}$ of DHA. Compared with the DHA therapy group, the DHA+miR-29b combination therapy group had significantly lower Mcl-1L gene expression (Fig. 4A). The Mcl-1S gene expression level increased; in particular, it significantly increased $48 \mathrm{~h}$ after DHA therapy and $24 \mathrm{~h}$ and $48 \mathrm{~h}$ after DHA $+m i R-29 b$ combination therapy. The Mcl-1S expression levels were significantly higher in the DHA+miR-29b combination therapy group than in the DHA therapy group at $24 \mathrm{~h}$ and $48 \mathrm{~h}$ (Fig. 4B). The Mcl-1S:Mcl-1L ratio increased in the DHA $+m i R-29 b$ group at all time points. In particular, it was significantly higher at $24 \mathrm{~h}$ and $48 \mathrm{~h}$ in the $\mathrm{DHA}+m i R-29 b$ group than in the control and DHA groups (Fig. 4C).

In the FRH0201 cell line, Mcl-1L gene expression also decreased after DHA therapy and DHA+miR-29b combination therapy. In particular, it was significantly lower at $24 \mathrm{~h}, 48 \mathrm{~h}$ and $72 \mathrm{~h}$ after DHA therapy and $72 \mathrm{~h}$ after DHA+miR-29b combination therapy (Fig. 4D). Mcl-1S gene expression increased in each treatment group. In particular, it was significantly higher in the DHA therapy group at $48 \mathrm{~h}$ and $72 \mathrm{~h}$ and in the combination therapy group at $24 \mathrm{~h}, 48 \mathrm{~h}$ and $72 \mathrm{~h}$. Compared with the DHA group, Mcl-1S expression was significantly higher at $24 \mathrm{~h}, 48 \mathrm{~h}$ and $72 \mathrm{~h}$ in the DHA+miR-29b group (Fig. 4E). Compared with the control group, the Mcl-1S:Mcl-1L ratio increased in the treatment groups at different times. In particular, it was significantly higher in the DHA group at $48 \mathrm{~h}$ and $72 \mathrm{~h}$ and in the DHA+miR-29b group at $24 \mathrm{~h}$ and $48 \mathrm{~h}$. Compared with the DHA therapy group, Mcl-1S expression significantly increased at $24 \mathrm{~h}$ and $48 \mathrm{~h}$ in the combination therapy group (Fig. 4F).

\section{Effects of DHA therapy and DHA+miR-29b combination therapy on $\mathrm{Mcl}-1$ protein expression profiles in HUCCT-1 and FRH0201 cells}

Western blotting analysis confirmed the presence of Mcl-1L and Mcl-1S protein expression in HUCCT-1 and FRH0201 cells. In the HUCCT-1 cell line, DHA therapy and DHA+miR-29b combination therapy significantly decreased Mcl-1L protein expression, whereas Mcl-1S protein expression was increased (Fig. 5A,B). The Mcl-1S:Mcl-1L ratio was significantly higher in the DHA and DHA $+m i R-29 b$ groups (Fig. 5C).

In the FRH0201 cell line, Mcl-1L protein expression was also significantly decreased after DHA therapy (Fig. 5D,E). 

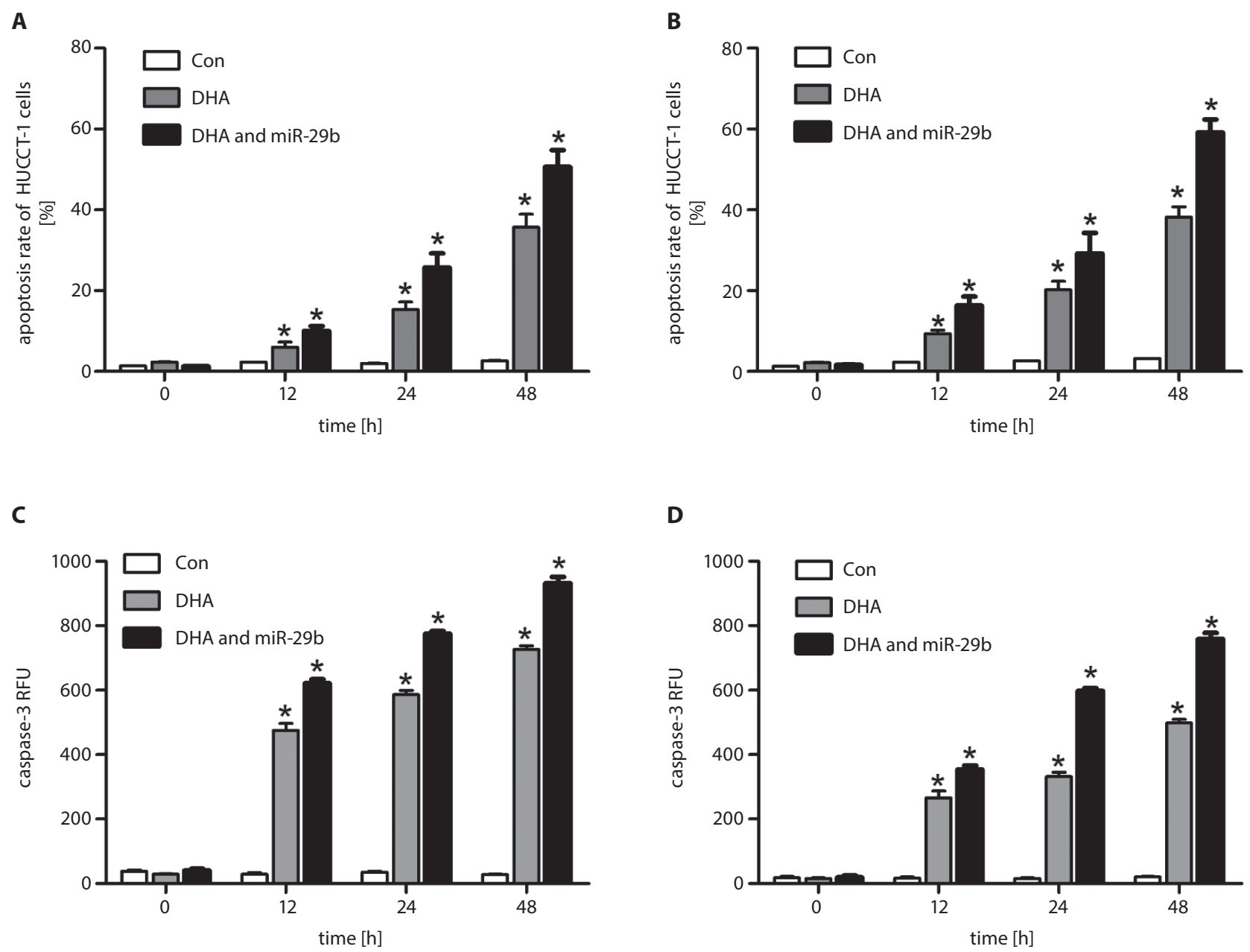

Fig. 3. Effects of DHA therapy and DHA+miR-29b combination therapy on the apoptosis of HUCCT-1 and FRH0201 cells. Changes in the apoptosis rate of HUCCT-1 (A) and (C) and on FRH0201 cells (B) and (D) at different time points after $20 \mu \mathrm{mol} / \mathrm{L}$ of DHA therapy or DHA+miR-29b combination therapy

${ }^{*} p<0.05$ vs control group.

After DHA $+m i R-29 b$ combination therapy, Mcl-1L protein expression was significantly higher than that after DHA therapy (Fig. 5D,E). The Mcl-1S protein expression level was significantly higher in each treatment group, and it was significantly higher in the combination therapy group than in the DHA therapy group (Fig. 5D,E). The Mcl-1S:Mcl-1L ratio was significantly higher in the treatment groups compared with the control group, and it was significantly higher in the combination therapy group than in the DHA therapy group (Fig. 5F).

\section{Discussion}

The DHA has a variety of potent anti-tumor effects. ${ }^{5-7}$ However, whether DHA can suppress cholangiocarcinoma or induce apoptosis of cholangiocarcinoma cells remains unclear. As a key regulator of Mcl-1 gene expression, we speculated that $m i R-29 b$ may play a synergistic role with DHA in suppressing the growth of cholangiocarcinoma cells, although its underlying mechanism requires further investigation. ${ }^{19}$ In our current experiment, treatment with DHA and $m i R-29 b$ decreased the proliferation of cholangiocarcinoma cells over time, along with an increase in cell growth inhibition rate. The proliferative activity of cholangiocarcinoma cells negatively correlated with the duration of DHA therapy, showing obvious proliferation-suppressing and apoptosis-promoting effects.

Tumorigenesis is associated with uncontrolled cell proliferation and apoptosis. Suppressing tumor-cell proliferation and inducing apoptosis are key methods for controlling and treating tumors, as well as being required indicators in screening for anti-cancer drugs. Many signal regulatory pathways are involved in apoptosis. For instance, p53 may activate apoptosis, and Bcl-2 and Bcl-XL - which belong to the anti-apoptosis family - can suppress apoptosis. These pathways can ultimately increase the release of mitochondrial cytochrome $\mathrm{C}$ and enhance activation of downstream caspases, which ultimately induces apoptosis. ${ }^{20,21}$ As a member of the Bcl-2 apoptosis regulator gene family, the anti-apoptosis gene Mcl-1 has similar sequence and functions as other $\mathrm{Bcl}-2$ genes and 
A
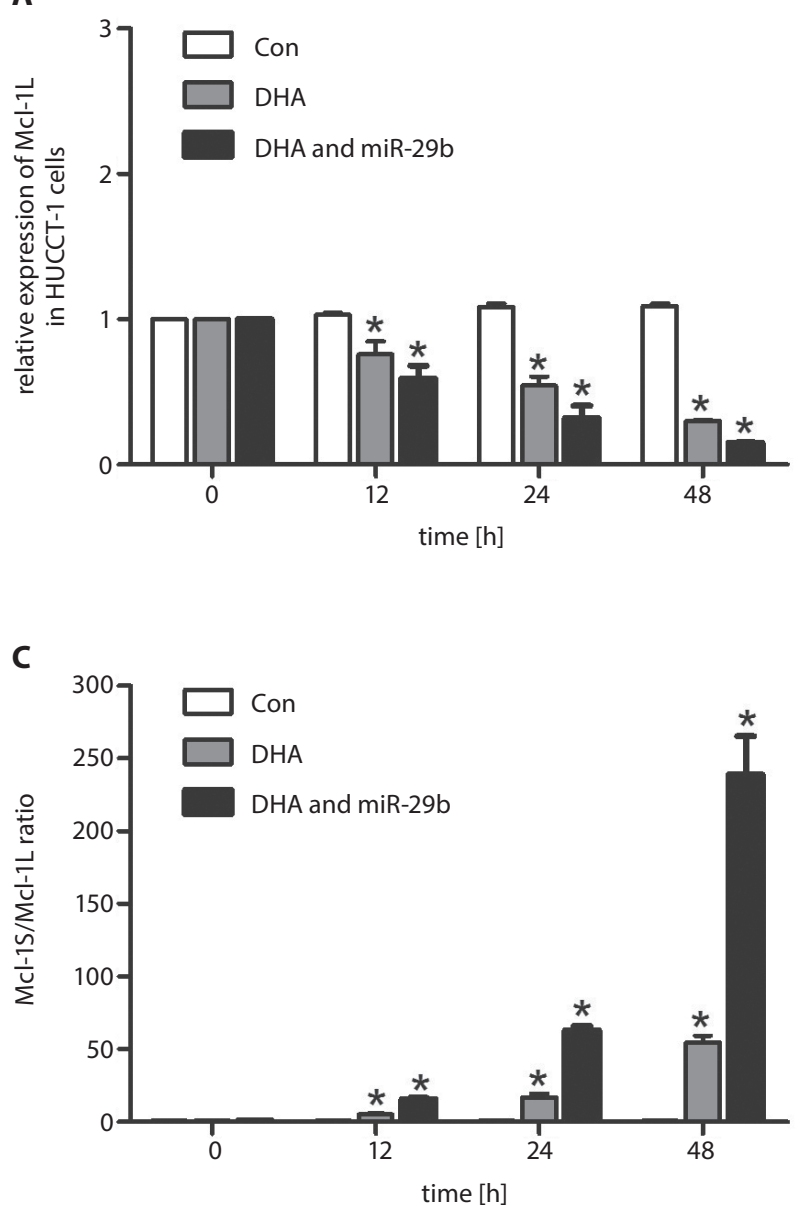

$\mathbf{E}$

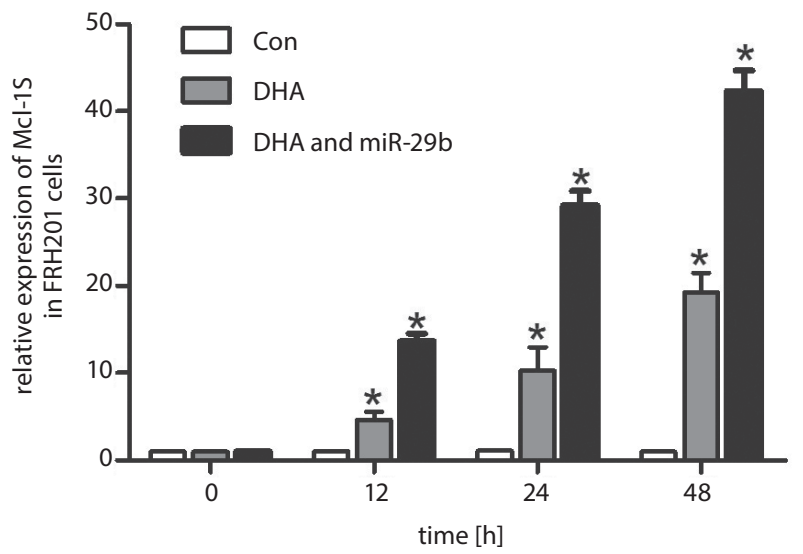

B

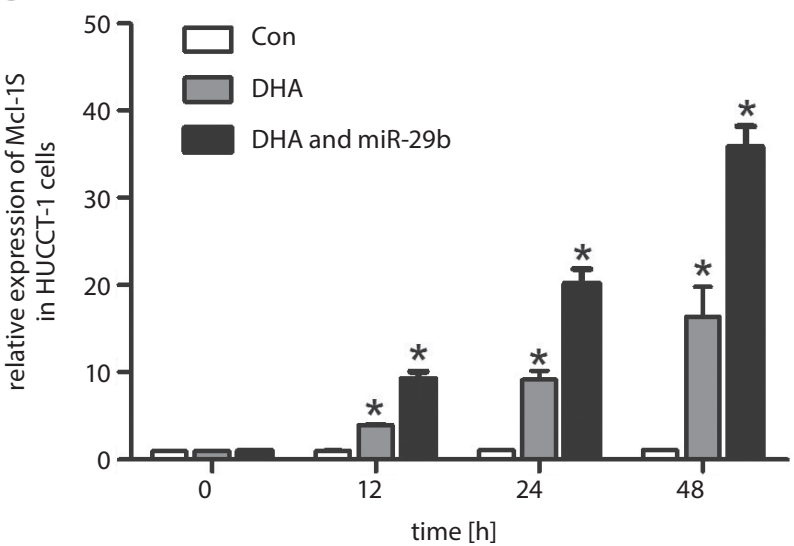

D

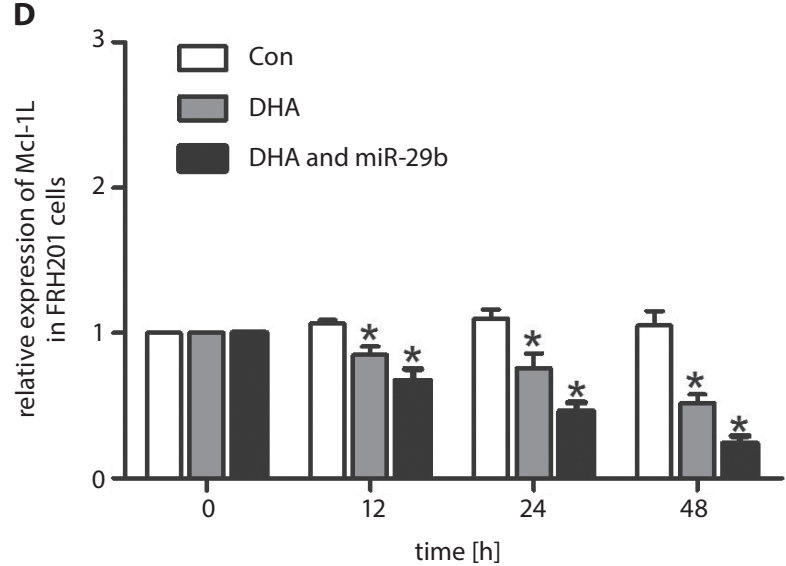

$\mathbf{F}$

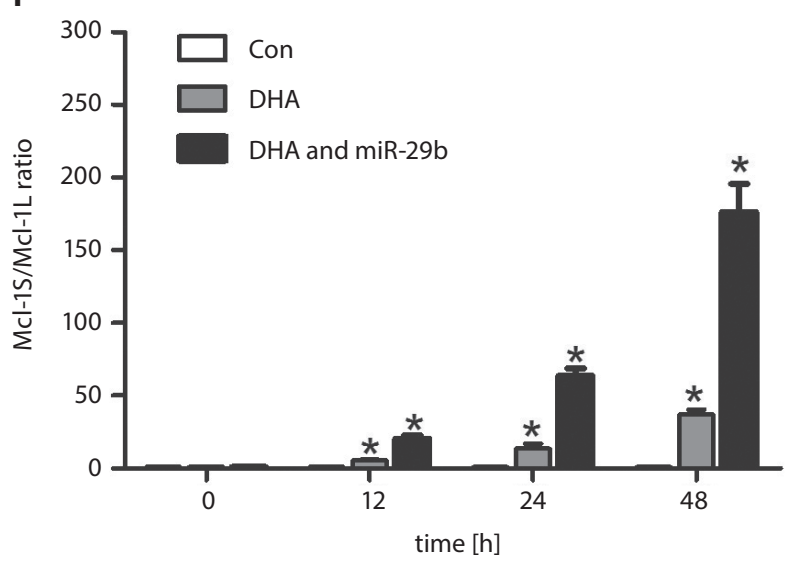

Fig. 4. Effects of DHA therapy and DHA+miR-29b combination therapy on mRNA expression of Mcl-1L and Mcl-1S. A. Effects of DHA therapy and DHA+miR-29b combination therapy on Mcl-1L mRNA expression at different time points. B. Effects of DHA therapy and DHA+miR-29b combination therapy on Mcl-1S mRNA expression at different time points. C. Changes in Mcl-1S:Mcl-1L ratio at different time points. D. Effects of DHA therapy and DHA+miR-296 combination therapy on Mcl-1L mRNA expression at different time points. E. Effects of DHA therapy and DHA+miR-29b combination therapy on Mcl-1S mRNA expression at different time points. F. Changes in Mcl-1S:Mcl-1L ratio at different time points

${ }^{*} \mathrm{p}<0.05$ vs control group

plays a key role in apoptosis. The Mcl-1 gene has 4 transcripts - Mcl-1-001-003 and Mcl-1-201; Mcl-1-003 does not encode protein products, whereas $\mathrm{Mcl}-1-001$ is the corresponding mRNA of Mcl-1L and $\mathrm{Mcl}-1-002$ is the corresponding mRNA of Mcl-1S. Although Mcl-1L and Mcl-1S are encoded by the same gene, they have opposite functions: the former is pro-apoptotic and the latter is antiapoptotic. Mcl-1 pre-mRNA undergoes alternative splicing events to produce 2 proteins - the splicing variant Mcl-1S and the non-spliced Mcl-1L. Thus, in normally growing 


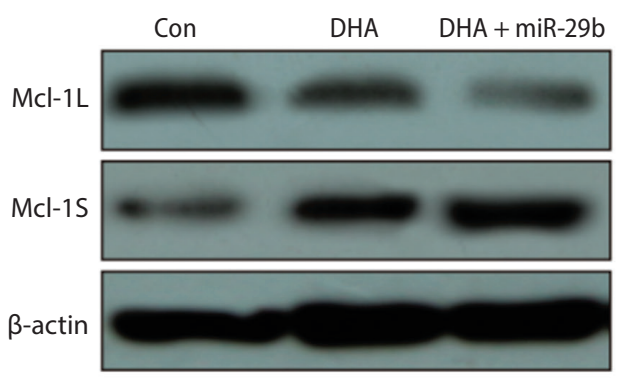

D

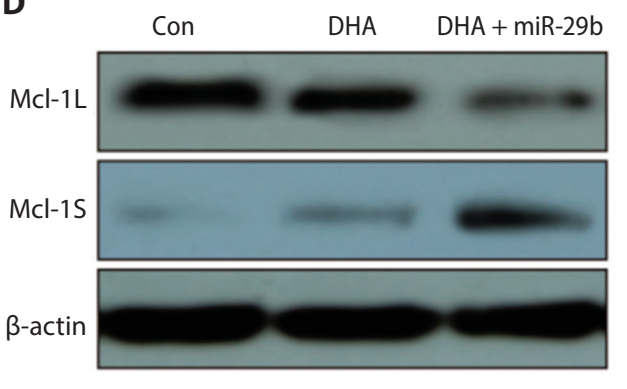

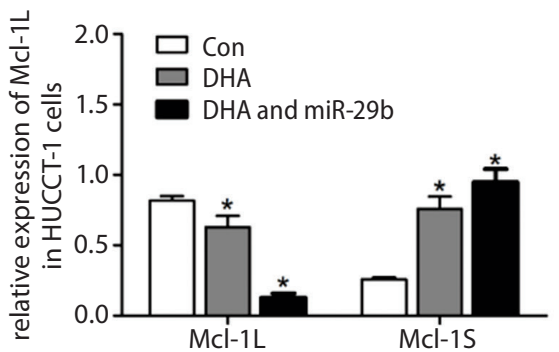

E

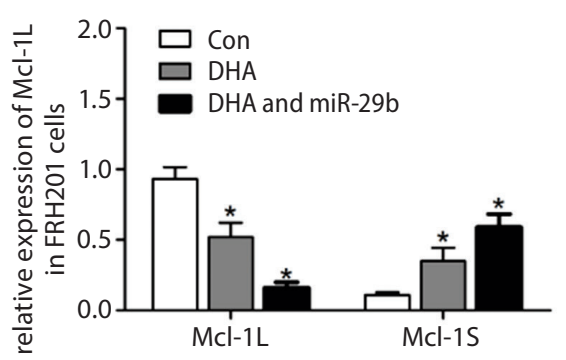

C

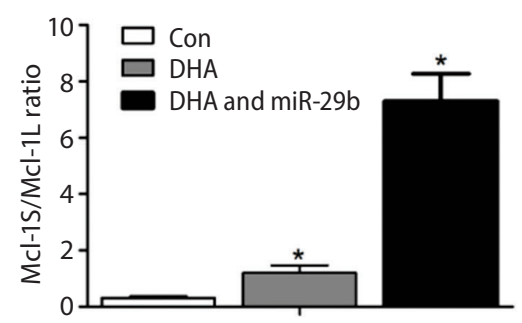

$\mathbf{F}$

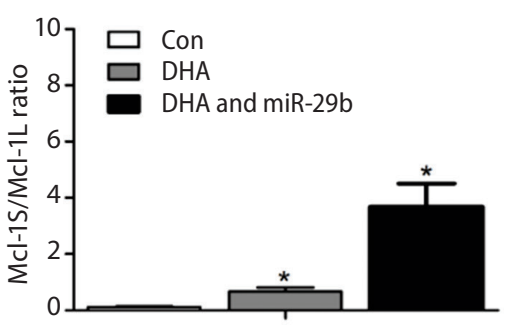

Fig. 5. A and B. Effects of DHA therapy and DHA+miR-29b combination therapy on MCl-1L and Mcl-1S protein expression. C. Changes in Mcl-1S:Mcl-1L ratio. $\mathrm{D}$ and $\mathrm{E}$. Effects of DHA therapy and DHA+miR-29b combination therapy on Mcl-1L and Mcl-1S protein expression. F. Changes in Mcl-1S:Mcl-1L ratio

${ }^{*} p<0.05$ vs control group.

tumor cells, the expression of Mcl-1L is higher than that of Mcl-1S. Therefore, Mcl-1L is also known as Mcl-1. The ratio between Mcl-1S and Mcl-1L determines the fate of Mcl-1-expressing cells. ${ }^{22-24}$

The anti-apoptotic protein Mcl-1 is highly expressed in cholangiocarcinoma cells, suggesting that the development of cholangiocarcinoma is closely correlated with the dysregulated expression of $\mathrm{Mcl}-1 .{ }^{25}$ In our previous study, we found that DHA induced apoptosis of QBC939 cells by affecting the apoptosis-related protein Mcl-1; as a result, the proportion of Mcl-1S in Mcl-1 was significantly higher. Meanwhile, the proliferation of QBC939 cells was markedly suppressed and apoptosis was enhanced. It was speculated that the occurrence of QBC939 apoptosis could be attributed to abnormal Mcl-1 protein expression due to the effect of DHA, and the proportion of $\mathrm{Mcl}-1 \mathrm{~L}$ and $\mathrm{Mcl}-1 \mathrm{~S}$ proteins in cells determines the fate of cells. ${ }^{16}$

The Mcl-1 mRNA expression profile was also affected by the intervention. The mRNA for the synthesis of the Mcl-1S protein was significantly higher in the DHAtreated cholangiocarcinoma cells, along with a significant increase in the Mcl-1S protein expression level. As a result, the proportion of Mcl-1S in Mcl-1 was significantly higher. It was therefore speculated that DHA might induce the apoptosis of cholangiocarcinoma cells by upregulating the proportion of Mcl-1S in Mcl-1. ${ }^{16}$ To rule out experimental error in a single cell line, to validate whether DHA has a definite pro-apoptotic effect on cholangiocarcinoma cells, and to confirm whether the changes in Mcl-1-related expression promote apoptosis, in the current study, we used 2 cholangiocarcinoma cell lines: HUCCT-1 and FRH0201. Our experiments confirmed that DHA had potent growth-inhibiting and apoptosis-promoting effects on these 2 cholangiocarcinoma cell lines; meanwhile, DHA therapy significantly increased $\mathrm{Mcl}-1 \mathrm{~S}$ expression in these 2 cell lines. These findings were consistent with our previous study on QBC939 cells.

Mott et al. reported that the expression of $m i R-29 b$ was higher in a human immortalized, non-malignant cholangiocyte $\mathrm{H} 69$ cell line, but was decreased in a malignant cholangiocarcinoma KMCH cell line. ${ }^{14}$ When $m i R-29 b$ was overexpressed in $\mathrm{KMCH}$ cells, the protein expression of Mcl-1, an anti-apoptotic Bcl-2 family member, was significantly lower, along with increased sensitivity to tumor necrosis factor (TNF)-related apoptosis-inducing ligand (TRAIL). Many studies have confirmed that the downregulated expression of $m i R-29 b$ in malignant cholangiocarcinoma cells is directly associated with the high expression of anti-apoptotic Mcl-1 protein in tumor cells. The miR-29b can also directly exert its effect on Mcl-1 gene 3'-UTR, whose overexpression, however, has no obvious effect on Mcl-1 mRNA. ${ }^{12}$ The expression of $m i R-29 b$ is low in normally growing tumor cells. Many studies have shown that the expression of Mcl-1 is controlled by the small endogenous RNA molecule miR-29, and that the high expression of miR-29 markedly decreases the expression of Mcl-1L in cholangiocarcinoma cells. In our current study, we applied $m i R-29 b$ to transfect the DHA-treated cholangiocarcinoma cells and found that 
$\mathrm{DHA}+m i R-29 b$ combination therapy markedly affected the mRNA expression profiles of Mcl-1 in both cell lines. More specifically, it significantly increased the expression level of mRNA, directing the synthesis of the Mcl-1S protein and thus increasing the Mcl-1S:Mcl-1L ratio. Flow cytometry revealed that DHA therapy and DHA $+m i R-29 b$ combination therapy significantly increased the apoptosis of cholangiocarcinoma cells in a time-dependent manner. The pro-apoptotic effect was more prominent in the combination therapy group than in the DHA therapy group. Our experiment also showed that the inhibitory effects of DHA and DHA $+m i R-29 b$ on the proliferation of cholangiocarcinoma cells were achieved by inducing apoptosis, and that the pro-apoptotic effect could be enhanced after combination therapy with $m i R-29 b$.

In summary, our study confirmed that DHA and $m i R-29 b$ have a pro-apoptotic effect on cholangiocarcinoma cells, which may be because the DHA/miR-29b/Mcl-1 pathway changes the Mcl-1 gene expression profile by upregulating the expression of the pro-apoptotic protein Mcl-1S, thus increasing the proportion of Mcl-1S protein among the total Mcl-1 protein. However, due to the complexity of the cancer cell signaling pathways and their regulatory mechanisms, more relevant studies from different perspectives are warranted.

\section{ORCID iDs}

Kezhou Li (10 https://orcid.org/0000-0002-5340-1129 Hui Hu (1) https://orcid.org/0000-0002-2772-7387

Zongding Wang (1) https://orcid.org/0000-0002-1952-546X

Chunlu Tan (1) https://orcid.org/0000-0002-1440-0430

Xubao Liu (10) https://orcid.org/0000-0002-6266-7519

Hao Zhang (i) https://orcid.org/0000-0003-1912-6036

\section{References}

1. Lunsford KE, Court C, Lee YS, et al. Propensity-matched analysis of patients with mixed hepatocellular-cholangiocarcinoma and hepatocellular carcinoma undergoing liver transplantation. Liver Transpl. 2018;24(10):1384-1397.

2. Kato A, Shimizu $H$, Ohtsuka $M$, et al. Surgical resection after downsizing chemotherapy for initially unresectable locally advanced biliary tract cancer: A retrospective single-center study. Ann Surg Oncol. 2013;20(1):318-324.

3. Yan X, Li P, Zhan Y, et al. Dihydroartemisinin suppresses STAT3 signaling and $\mathrm{Mcl}-1$ and survivin expression to potentiate ABT-263-induced apoptosis in non-small cell lung cancer cells harboring EGFR or RAS mutation. Biochem Pharmacol. 2018;150:72-85.

4. Bergquist A, von Seth V. Epidemiology of cholangiocarcinoma. Best Prac Res Clin Gastroenterol. 2015;9(2):221-232.

5. Wallender E, Vucicevic K, Jagannathan $P$, et al. Predicting optimal dihydroartemisinin-piperaquine regimens to prevent malaria during pregnancy for human immunodeficiency virus-infected women receiving efavirenz. J Infect Dis. 2018;217(6):964-972.
6. Feng MX, Hong JX, Wang Q, et al. Dihydroartemisinin prevents breast cancer-induced osteolysis via inhibiting both breast cancer cells and osteoclasts. Sci Rep. 2016;6:19074.

7. Qin G, Zhao C, Zhang L, et al. Dihydroartemisinin induces apoptosis preferentially via a Bim-mediated intrinsic pathway in hepatocarcinoma cells. Apoptosis. 2015;20(8):1072-1086.

8. Chen SS, Hu W, Wang Z, Lou X-E, Zhou H-J. p8 attenuates the apoptosis induced by dihydroartemisinin in cancer cells through promoting autophagy. Cancer Biol Ther. 2015;16(5):770-779.

9. Hu W, Chen SS, Zhang JL, Lou X-E, Zhou H-J. Dihydroartemisinin induces autophagy by suppressing NF-KB activation. Cancer Lett. 2014;343(2):239-248.

10. Morciano G, Giorgi C, Balestra D, et al. Mcl-1 involvement in mitochondrial dynamics is associated with apoptotic cell death. Mol Biol Cell. 2016;27(1):20-34.

11. de Necochea-Campion R, Diaz Osterman CJ, Hsu HW, et al. AML sensitivity to YM155 is modulated through AKT and Mcl-1. Cancer Lett. 2015;366(1):44-51.

12. Nijhuis A, Curciarello R, Mehta S, et al. MCL-1 is modulated in Crohn's disease fibrosis by miR-29b via IL- 6 and IL-8. Cell Tissue Res. 2017; 368(2):325-335.

13. Escudero $S$, Zaganjor E, Lee $S$, et al. Dynamic regulation of longchain fatty acid oxidation by a noncanonical interaction between the MCL-1 BH3 helix and VLCAD. Mol Cell. 2018;69(5):729-743.

14. Mott JL, Kobayashi S, Bronk SF, Gores GJ. miR-29 regulates Mcl-1 protein expression and apoptosis. Oncogene. 2007;26(42):6133-6140.

15. Okamoto K, Miyoshi K, Murawaki Y. miR-29b, miR-205 and miR-221 enhance chemosensitivity to gemcitabine in $\mathrm{HuH} 28$ human cholangiocarcinoma cells. PLoS One. 2013;8(10):e77623.

16. Hu H, Tan C, Liu X, Luo F, Li K. Upregulation of the MCL-1S protein variant following dihydroartemisinin treatment induces apoptosis in cholangiocarcinoma cells. Oncol Lett. 2015;10(6):3545-3550.

17. Livak KJ, Schmittgen TD. Analysis of relative gene expression data using real-time quantitative PCR and the 2(-delta delta C(T)) method. Methods. 2001;25(4):402-408.

18. Schmittgen TD, Livak KJ. Analyzing real-time PCR data by the comparative C(T) method. Nat Protoc. 2008;3(6):1101-1108.

19. Tian F, Chen J, Zheng S, et al. miR-124 targets GATA6 to suppress cholangiocarcinoma cell invasion and metastasis. BMC Cancer. 2017;17(1):175.

20. Renault TT, Teijido O, Antonsson B, Dejean LM, Manon S. Regulation of Bax mitochondrial localization by $\mathrm{Bcl}-2$ and $\mathrm{Bcl}-\mathrm{x}(\mathrm{L})$ : Keep your friends close but your enemies closer. Int J Biochem Cell Biol. 2013; 45(1):64-67.

21. Liu D. Effects of procyanidin on cardiomyocyte apoptosis after myocardial ischemia reperfusion in rats. BMC Cardiovasc Disord. 2018; 18(1):35.

22. Palve V, Mallick S, Ghaisas G, Kannan S, Teni T. Overexpression of Mcl-1L splice variant is associated with poor prognosis and chemoresistance in oral cancers. PLoS One. 2014;9(11):e111927.

23. Haydn T, Metzger E, Schuele R, Fulda S. Concomitant epigenetic targeting of LSD1 and HDAC synergistically induces mitochondrial apoptosis in rhabdomyosarcoma cells. Cell Death Dis. 2017;8(6):e2879.

24. Chen S, Dai Y, Pei XY, Grant S. Bim upregulation by histone deacetylase inhibitors mediates interactions with the $\mathrm{Bcl}-2$ antagonist ABT-737: Evidence for distinct roles for $\mathrm{BCl}-2, \mathrm{BCl}-\mathrm{xL}$, and $\mathrm{Mcl}-1$. Mol Cell Biol. 2009;29(23):6149-6169.

25. Rizvi S, Yamada D, Hirsova P, et al. A hippo and fibroblast growth factor receptor autocrine pathway in cholangiocarcinoma. J Biol Chem. 2016;291(15):8031-8047. 